\title{
The pivotal role of pedicled perforator flaps amidst irradiation
}

\begin{abstract}
Sir,
Sacral teratomas transforming into malignant adenocarcinoma is extremely rare..$^{[1]}$ A 50 -year-old female presented with such a case involving the lower 3 sacral vertebrae infiltrating into the rectum. Despite radiotherapy, she had pain and progressive loss of bladder control.

Surgical plan included tumour resection with bowel diversion with reconstruction:

1. Separation of abdominal and pelvic cavities and filling of the pelvic dead space.

2. To fill volume and provide cover for the irradiated sacral wound created after tumour resection.

A combined abdominosacral approach was used. ${ }^{[2]}$ First, with the abdominal approach, inferiorly-based right vertical rectus abdominis myocutaneous (VRAM) flap was harvested. This was away from the site of irradiation and the left side was used for colostomy. Abdominoperineal resection with sigmoid colostomy was done. The VRAM flap was then folded and sutured to the margins of the sacral defect. Turning the patient prone, sacral tumour was resected, preserving S2, S3 roots, while sacrificing both left superior and inferior gluteal vessels with removal of major portions of gluteal muscles and right superior gluteal artery [Figure 1].
\end{abstract}

After $15 \mathrm{~h}$ of surgery with a 10-pint transfusion, considerations for closure included a microvascular or a pedicled perforator flap transfer. Two factors against 


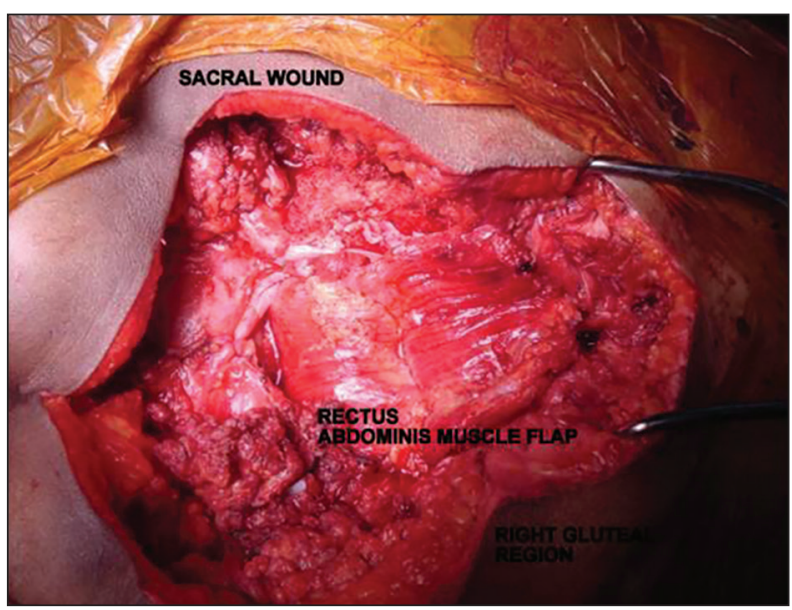

Figure 1: Sacral approach showing excised tumour and folded rectus abdominis muscle flap sutured to the sacral defect

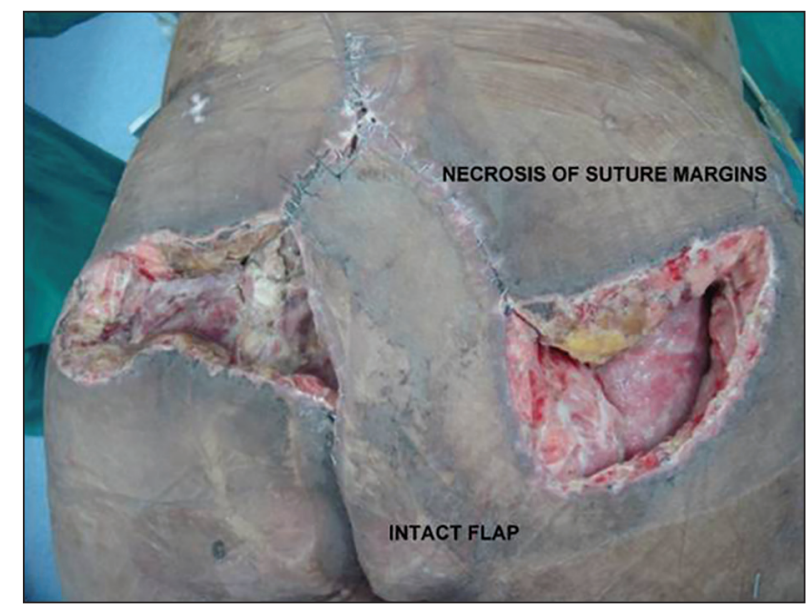

Figure 2: Necrosis of the sutured margins around the flap, necrosis of gluteal muscles and fat with herniation of bowel into the pelvis; however, IGAP perforator plus flap stands robust

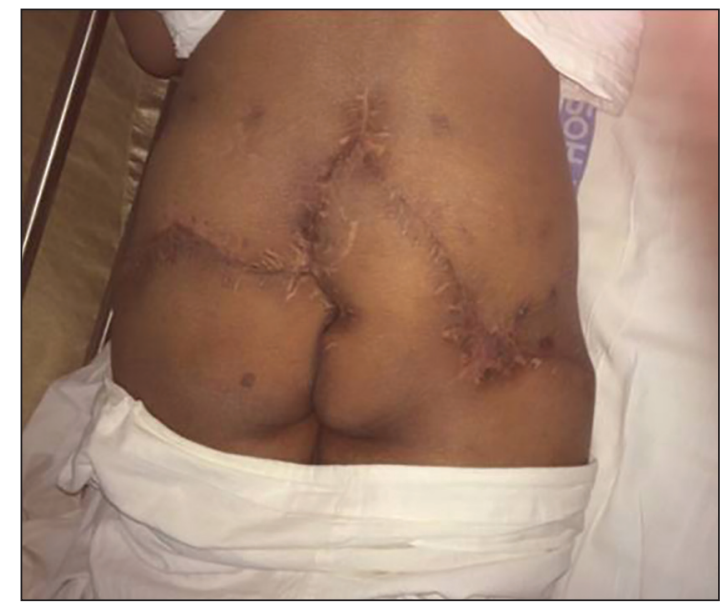

Figure 3: Local wound therapy with negative pressure dressings and secondary closure

choosing the former were time and the lack of recipient vessels. Thus, a right inferior gluteal artery perforator (IGAP) plus flap was designed. Perforators of inferior gluteal artery
(IGA) were seen branching from it and the flap was dissected antegrade. IGA was preserved to supply the residual tissues. A larger flap was designed to allow tension-free closure in the irradiated area and to fill the dead space.

On postoperative day 5 , the patient had paralytic ileus and necrosis of sacral suture lines. When the sacral wounds were opened for debridement, bowel loops were seen herniated through the pelvic brim from one side of the rectus muscle into the gluteal wound. Laparotomy with bowel decompression was done. A prolene mesh was sutured to the pelvic brim to prevent bowel from entering the pelvis again. There was widespread necrosis of the remaining gluteal fat and muscles, but the IGAP flap stood robust [Figure 2]. With repeated debridements and negative pressure wound therapy (NPWT) dressings, the sacral wound was closed secondarily with addition of small skin graft. She developed burst abdomen as well, treated by NPWT and grafting [Figure 3].

This case highlights the utility of perforator flaps amidst: ${ }^{[3,4]}$

1. Time constraints with deteriorating haemodynamics.

2. Radiation and infection.

3. Preservation of end arteries.

4. Not violating other vascular territories (here posterior thigh flap) thus preserving life-hoats.

\section{Financial support and sponsorship} Nil.

\section{Conflicts of interest}

There are no conflicts of interest.

\section{Leena Jain, Samir M Kumta, Shrirang K Purohit, Manik Menezes, Mehul Bhansali}

Department of Plastic Surgery, Lilavati Hospital and Research Centre, ${ }^{1}$ Department of Surgical Oncology, Jaslok Hospital and Research Centre, Mumbai, Maharashtra, India

Address for correspondence:

Dr. Leena Jain, No. 301, $3^{\text {rd }}$ Floor C Wing, Dheeraj Presidency, MG Road, Kandivali West, Mumbai - 400 067, Maharashtra, India E-mail: link.jain@gmail.com

\section{REFERENCES}

1. Wang LJ, Chu SH, Ng KF, Wong YC. Adenocarcinomas arising from primary retroperitoneal mature teratomas: CT and MR imaging. Eur Radiol 2002;12:1546-9. 
2. Li GD, Chen K, Fu D, Ma XJ, Sun MX, Sun W, et al. Surgical strategy for presacral tumors: Analysis of 33 cases. Chin Med J (Engl) 2011;124:4086-91.

3. Wagstaff MJ, Rozen WM, Whitaker IS, Enajat M, Audolfsson T, Acosta R. Perineal and posterior vaginal wall reconstruction with superior and inferior gluteal artery perforator flaps. Microsurgery 2009;29:626-9.

4. Unal C, Yirmibesoglu A, Ozdemir J, Hasdemir M. Superior and inferior gluteal artery perforator flaps in gluteal and perianal/perineal hydradenitis suppurativa lesions. Microsurgery 2011;31:539-44.

This is an open access article distributed under the terms of the Creative Commons Attribution-NonCommercial-ShareAlike 3.0 License, which allows others to remix, tweak, and build upon the work non-commercially, as long as the author is credited and the new creations are licensed under the identical terms.

\begin{tabular}{|l|l|}
\hline \multicolumn{3}{|c|}{ Access this article online } \\
\hline Quick Response Code: & Website: \\
\hline & www.ijps.org \\
\cline { 2 - 2 } & DOI: \\
\hline
\end{tabular}

How to cite this article: Jain L, Kumta SM, Purohit SK, Menezes M, Bhansali M. The pivotal role of pedicled perforator flaps amidst irradiation. Indian J Plast Surg 2015;48:322-4. 